\title{
$X$ inactivation phenotype in carriers of Pelizaeus-Merzbacher disease: skewed in carriers of a duplication and random in carriers of point mutations
}

\author{
Karen Woodward ${ }^{1}$, Karen Kirtland ${ }^{1}$, Stephen Dlouhy ${ }^{2}$, Wendy Raskind ${ }^{3}$, Thomas Bird $^{3}$, \\ Sue Malcolm ${ }^{1}$ and Dvorah Abeliovich ${ }^{1,4}$ \\ ${ }^{1}$ Institute of Child Health, London, UK; ${ }^{2}$ Indiana University School of M edicine, Indianapolis, USA ; ${ }^{3}$ University of \\ Washington, Seattle, USA; ${ }^{4}$ Hadassah Hebrew University Hospital and Medical School, Jerusalem, Israel
}

Pelizaeus-Merzbacher disease (PMD) is an X-linked recessive disease caused by coding sequence mutations in the PLP gene, sub-microscopic duplications of variable sizes including the PLP gene or very rarely deletions of the PLP gene. We analysed the $X$ inactivation pattern in blood of PMD female carriers with duplications and with point mutations. In the majority of duplication carriers (7/11), the $X$ chromosome bearing the duplication was preferentially inactivated, whereas a random pattern of $X$ inactivation was detected in point mutation carriers (3/3), a deletion carrier $(1 / 1)$, affected females (4/4) who did not have a recognised mutation and normal control females. However $2 / 5$ non-carrier female relatives of patients with a duplication, had skewed $X$ inactivation. The skewed pattern of inactivation observed in most duplication carriers and not in mutation carriers suggests a) that there is selection against those cells in which the duplicated $X$ chromosome is active and $b$ ) other expressed sequences within the duplicated region rather than mutant PLP may be responsible. Since the skewed $X$ inactivation did not segregate with the disease in two families and the pattern of $X$ inactivation was variable among the duplication carriers, the pattern $X$ inactivation is an unsuitable diagnostic tool for female carriers of PMD European Journal of Human Genetics (2000) 8, 449-454.

Keywords: Pelizaeus-Merzbacher disease; PMD; PLP; X inactivation; duplication; deletion

\section{Introduction}

Pelizaeus-Merzbacher disease (PMD; MIM 312080) is a recessive $X$-linked dysmyelinating disorder of the central nervous system (CNS). The gene implicated in PMD is PLP (proteolipid protein) on Xq22 encoding a major myelin protein in the CNS which, together with its splicing variant DM 20, is a hydrophobic integral membrane protein. ${ }^{1}$

Three different types of mutation have been identified in PMD patients. The majority of mutations (approximately $50 \%$ ) involve a duplication of the PLP gene. ${ }^{2-5}$ The duplica-

Correspondence: Dr Karen Woodward, Molecular Genetics Unit, Institute of Child Health, 30 Guilford Street, London, WC1N 1EH, UK. Tel: +44 207905 2222; Fax: +44 207404 6191; E-mail: kwoodwar@hgmp.mrc.ac.uk

Received 2 September 1999; revised 20 January 2000; accepted

9 February 2000 tions are variable in size but do not affect the coding sequence of the PLP gene ${ }^{5}$ and therefore it is an increased dosage of the PLP gene that is responsible for PMD. Sequence alterations in the PLP gene are found in $20-30 \%$ of patients. $^{3,4,6}$ Loss of PLP caused by a deletion ${ }^{7}$ or a null allele $^{8,9}$ has also been reported in a few cases. A few female carriers of point mutations exhibit some of the clinical features of PMD. ${ }^{10-12}$ There are also several reports of affected females with no identified mutation in the PLP gene; some cases were familial and others were sporadic. It has been suggested that these cases represent an autosomal recessive form of PMD. ${ }^{13-16}$

In several $X$-linked recessive disorders $X$ inactivation is skewed in asymptomatic carrier females, so that the $X$ bearing the mutation is preferentially inactivated. ${ }^{17}$ This is also found in carriers of cytogenetically detectable deletions 
and duplications on the $X$ chromosome. ${ }^{18,19}$ The skewed $X$ inactivation, in most cases, is a result of selection against cells with growth disadvantage. Carriers of PMD with a duplication have a submicroscopic chromosomal rearrangement which includes other coding sequences in addition to the PLP gene. In carriers of point mutations it is only the PLP gene that is affected. In the present study we analysed the pattern of $X$ inactivation in WBC of PMD carrier females with a duplication and with a point mutation in the PLP gene.

\section{Material and methods \\ The study group}

A total of 36 females was analysed:

(a) carrier females with duplications $(n=13)$ were all mothers of PMD affected sons. The duplication mutations were identified by FISH using the cosmid probe cU125A1 from the PLP gene. ${ }^{5}$ Some of the patients with duplications (PMD1,2,4,9) have been previously described. ${ }^{5}$ In the majority of carriers the duplication was tandem; families PMD1 and PMD5 were exceptional in that the duplicated segment was transposed to $\mathrm{Xq} 26$ and $\mathrm{Xp22.1}$, respectively. ${ }^{20}$ In families PMD22 and PMD23 the duplication was identified by quantitative $P C R^{5}$ and we were unable to determine the size of the duplication;

(b) a female carrier of a deletion mutation; ${ }^{7}$

(c) carrier females with point mutations $(n=3)$ were all mothers of affected sons. In these three families there was a substitution mutation, T181P in PMD12, L223P in PMD13 $^{6}$ and P173S ( $\rightarrow T$ nucleotide519) in PMD14 (C Schwartz, unpublished results, 1997);

(d) affected females ( $n=4$ ) with no duplications or identified point mutations;

(e) a group of normal control females comprised of noncarrier female relatives of patients with a duplication $(n=5)$, including a maternal grandmother and aunt of the patients PMD1 and PMD3, and a maternal aunt of patient PMD24 (we did not have a DNA sample from the mother of patient PMD24), and unrelated females $(n=10)$.

\section{$X$ inactivation analysis}

For $\mathrm{X}$ inactivation studies, DNA was obtained from lymphoblastoid cell lines or uncultured WBC. The androgen-receptor (AR) gene $X$-inactivation assay using Hpall-sensitive methylation was performed according to Allen et al. ${ }^{21}$ A VNTR polymorphism in the monoamine oxidase A gene (MAOA3), with adjacent Hpall-sensitive methylation sites on Xp11.4-11.23, ${ }^{22}$ was evaluated in subjects who were homozygous for AR. DNAs from males were used as control for complete Hpall digestion. Products were analysed on an $\mathrm{ABI} 377$ sequencer and the peak heights were analysed using

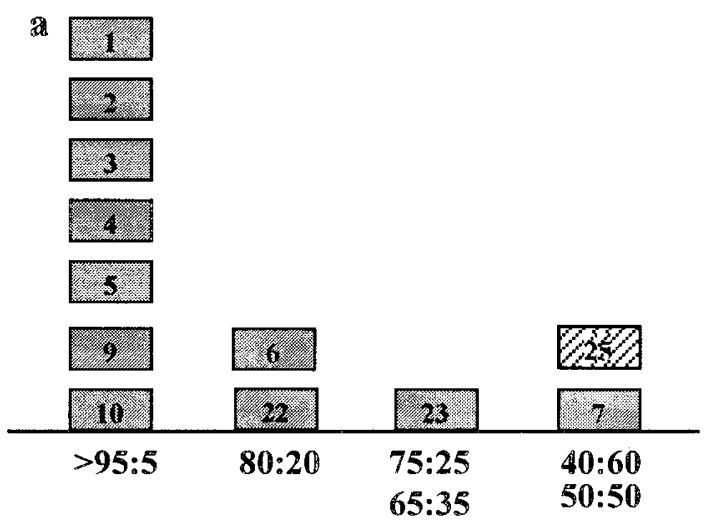

b

\begin{tabular}{|c|c|c|c|}
\hline $1-2$ & & & 3.2 \\
\hline $24-3$ & & $1-3$ & $3-3$ \\
\hline$>95: 5$ & $80: 20$ & $\begin{array}{l}75: 25 \\
65: 35\end{array}$ & $\begin{array}{l}40: 60 \\
50: 50\end{array}$ \\
\hline
\end{tabular}

c 66

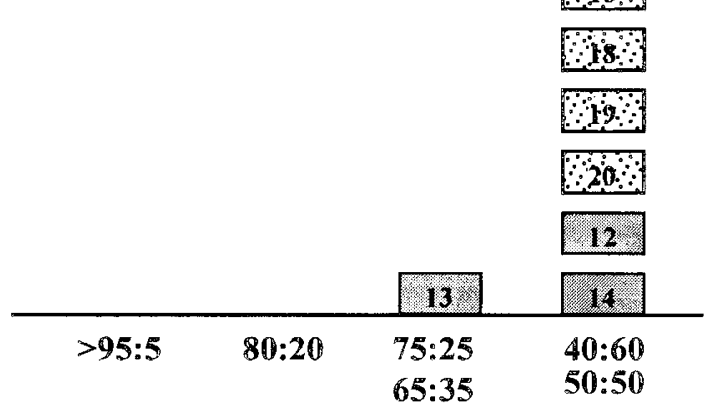

d

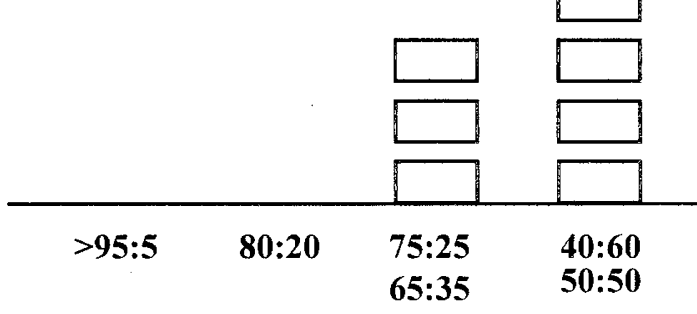

$\%$ of cells with the same $X$ chromosome inactive

Figure 1 The pattern of $X$ inactivation, a duplication carriers and the deletion carrier (PMD25); $\mathbf{b}$ non-carrier relatives of duplication carriers; c affected females (PMD16,18,19,20) and point mutation carriers PMD12,13,14); d normal female controls. The number in boxes refer to PMD family number. 
GeneScan and Genotyper software (PE Biosystems, Warrington, Cheshire, UK). Each assay was repeated 2-5times and the average values were cal culated.

\section{Analysis of $\mathbf{X}$ inactivation on metaphase chromosomes}

This assay was performed using a culture of skin fibroblasts. BrdU was applied $7 \mathrm{~h}$ before harvesting the cells. ${ }^{23} \mathrm{FISH}$ using the cosmid probe cU125A1 including the PLP gene was followed by mouse anti-BrdU antibody $(6 \mu \mathrm{g} / \mathrm{ml}$ ) (Roche Diagnostics Ltd, Lewes, East Sussex, UK) and texas-red antimouse IgG $(150 \mu \mathrm{g} / \mathrm{ml})$ (Vector Laboratories Ltd, Peterborough, UK). Cells were viewed using a Zeiss Axiophot fluorescent microscope with a triple-band pass filter.

\section{Characterisation of the size of the duplication}

The size of the duplications was determined by FISH using PAC and cosmid clones from the region around the PLP gene as previously described. ${ }^{5}$

\section{Results}

\section{The pattern of $X$ inactivation}

Thirty-one females were informative for the AR-(CAG) $n$ assay. Three females homozygous for AR were found to be heterozygous for the MAOA3 VNTR. Two females were not informative for either the AR or the MAOA3 gene. The pattern of $X$ inactivation for the 34 females is presented in Figure 1. Two duplication carriers with skewed $X$ inactivation were analysed for both $A R$ and MAOA3 and the results were identical. In one carrier (PMD1), the $X$ inactivation was completely skewed in DNA from a lymphoblastoid cell line, uncultured WBC and skin fibroblasts.

In 6/7 mother-son pairs with a duplication, the AR-(CAG) or the MAOA3-VNTR allele on the preferentially inactivated $X$ was the allele that their affected sons carry. In family PMD1, the maternal allele on the inactive $X$ was different from that of her PMD affected son due to recombination between the PLP genes on $\mathrm{Xq} 22$ and $\mathrm{Xq} 26$, which was confirmed by polymorphic markers from the $X$ chromosome (not shown). In the other carriers the alleles of the sons were unknown.

\section{Cytogenetic analysis of $X$ inactivation}

The carrier PMD1 had the duplicated segment transposed to Xq26. ${ }^{20}$ In her case, it was possible to directly determine which of her two $X$ chromosomes was preferentially inactivated using $\mathrm{FISH}$ combined with BrdU replication banding on metaphase chromosomes. In all 24 metaphase cells analysed, the late replicating (inactive) $X$ chromosome had two FISH signals, corresponding to Xq22 and Xq26 (Figure2).

\section{Characterisation of the duplication in female carriers with skewed and random $X$ inactivation}

To investigate the possibility that the genetic content of the duplication determines the pattern of $X$ inactivation, we compared their sizes and location. Lymphoblastoid cell lines were available from 9 of the 11 carriers, PMD1,2,3,4,5,9,10 with a completely skewed pattern of inactivation, PMD6 with a mildly skewed pattern and PMD7 with a random pattern.
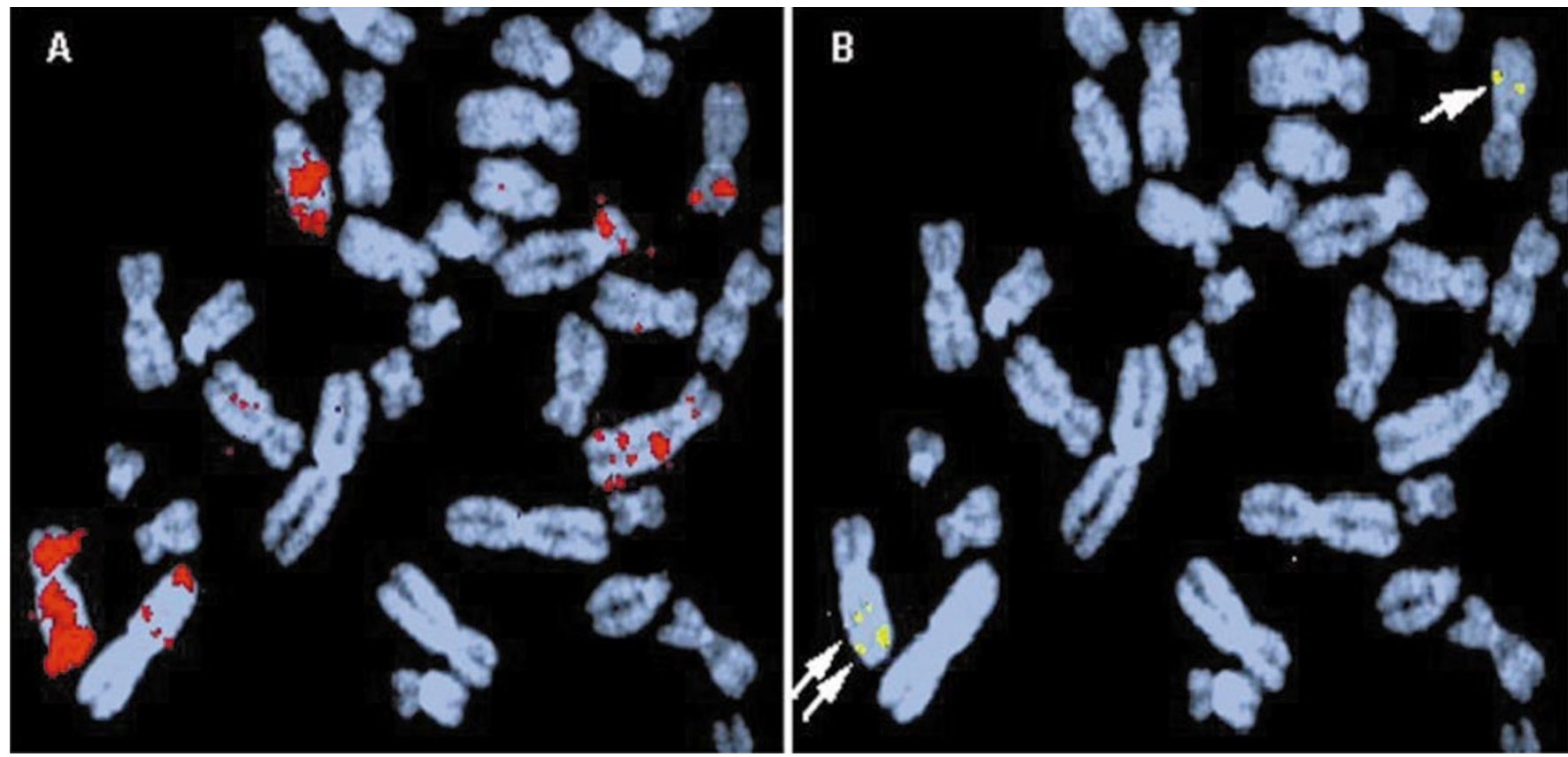

Figure 2 Metaphase chromosome from fibroblasts of PMD1 female carrier. A BrdU staining is shown in red and identifies the late replicating regions of DNA; $\mathbf{B}$ FISH of a PLP cosmid probe is shown by a yellow signal. The PLP gene duplication on Xq22 and Xq26 is shown on the late replicating (inactive) $X$ chromosome. 
The duplications were classified into groups according to their putative breakpoints (Figure3).

\section{Discussion}

Among the PMD carrier females, a marked difference between the two types of carrier emerged; female carriers with point mutations had random $X$ inactivation, whereas $7 / 11$ of duplication carriers had completely skewed $X$ inactivation and $2 / 11$ had a suggestively skewed pattern. In all cases the $X$ bearing the duplication was preferentially inactive. $A$ random pattern of $X$ inactivation was observed in the carrier of the del etion mutation. In several large studies of normal females, fewer than $10 \%$ showed skewing greater than $85 \% .^{24-27}$ The excess of duplication carriers with completely skewed $X$ inactivation as compared to the published control groups is highly significant.

Skewed $X$ inactivation may be a result of a stochastic event, a defect in the primary control of $X$ inactivation or a secondary effect due to cell selection after $X$ inactivation is established. ${ }^{17,28,29} \mathrm{~A}$ selection against cells carrying the mutation on the active $X$ might be the basis for the discrepancy between the carriers of point mutations and duplications. The PLP gene is not expressed in WBC, ${ }^{30}$ therefore it is not expected that point mutations in PLP would be a selective factor. The duplications, on the other hand, might affect the growth rate of PLP-non expressing cells due to a dosage effect of other genes within the duplicated segment. It is interesting to note that although the duplicated segments contain sequences that affect the pattern of $X$ inactivation, there is currently no indication that they have a major effect on the PMD phenotype of the affected boys. It is possible that in PLP-expressing cells such as those in the CNS, the $X$ inactivation pattern in asymptomatic carriers of PMD might be skewed regardless of type of mutation. A skewed X-inactivation pattern in the CNS has been suggested to occur in heterozygote females of the shaking (sh) pup, an animal model of PMD ${ }^{31}$ with a point mutation in the PLP gene.

A variableX inactivation phenotype was found in the WBC of duplication carriers. This has been noted in other $X$-linked recessive genes ${ }^{27,32,33}$ and it has been suggested to reflect incomplete penetrance due to other factors, genetic or stochastic. In PMD one such factor might be the genetic content of the duplicating segment. The duplication in PMD7 was among the largest ( $>1.2 \mathrm{Mb}$ ), the duplications in PMD1 and PMD5 were the smallest ( $<0.6 \mathrm{Mb})$, and they were overlapped by the duplication of PMD7. Yet, the carrier
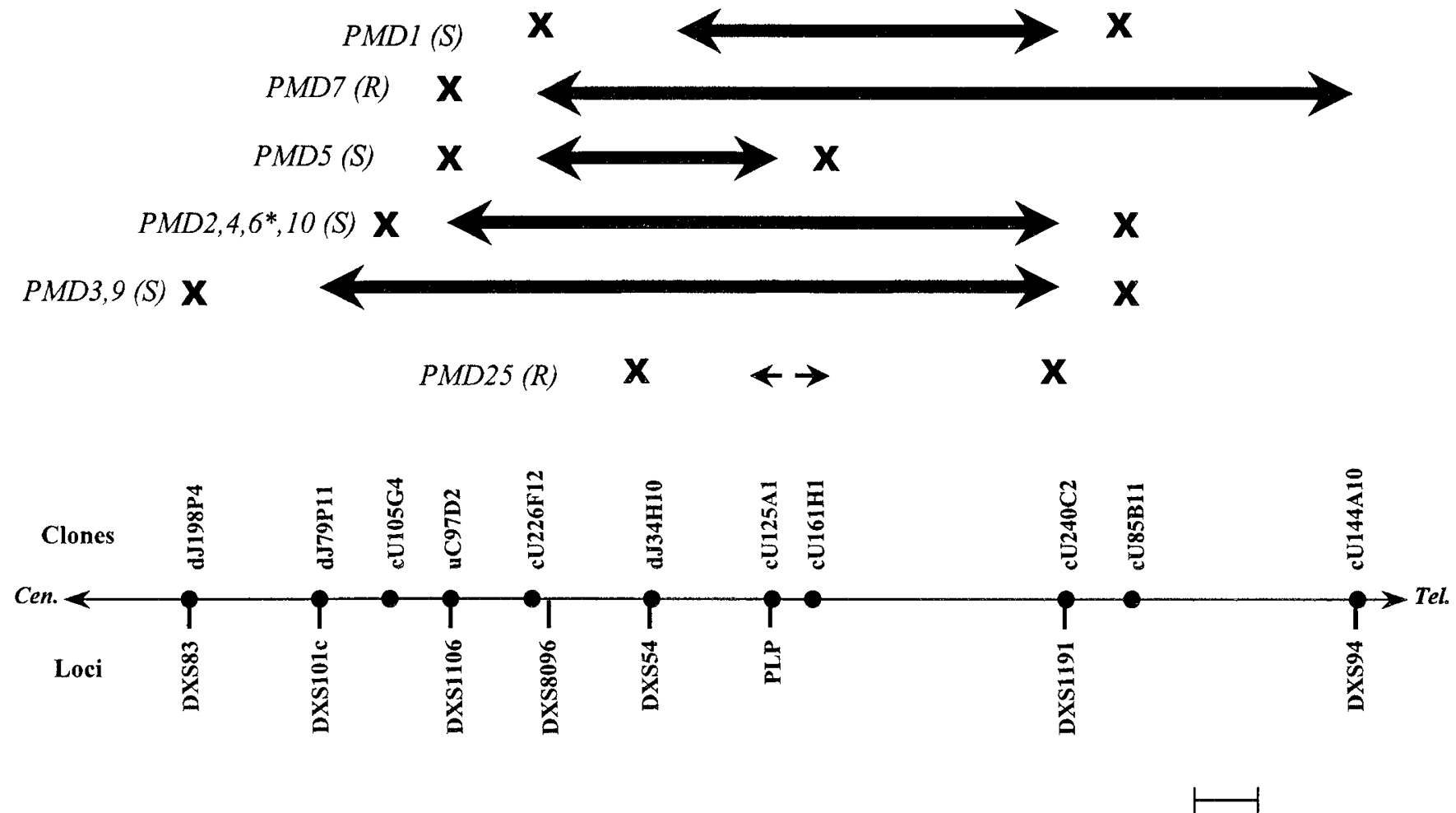

Approx. 100Kb

Figure 3 Map of the PLP region showing the extent of the duplication in nine patients and the deletion in patient PMD25. The minimum size of the duplication/deletion is shown by the arrowed line and the boundaries are marked by $X$. R indicates a random pattern of X-inactivation and S indicates a skewed pattern with * being mildly skewed and the rest completely skewed. 
female PMD7 had a random $X$ inactivation pattern and PMD1 and PMD5 had a completely skewed pattern. Although the duplication size and position of PMD6 is consistent with that of PMD2, 4 and 10, which have completely skewed inactivation, only a mildly skewed pattern of $X$ inactivation was observed in his carrier mother. These observations suggest that the increased dosage of a unique gene within the duplication is unlikely to be responsible for the skewing effect, unless the determinant factor is the breakpoints. The only possible location for a single gene would be beyond the proximal breakpoint of PMD7 but within the duplication of PMD2,3,4,5,6,9,10 and then the skewing in PMD1 may be due to the insertion into Xq26 and the mild skewing in PMD6 would have to be caused by another factor. An alternative explanation would be that the PMD duplication mutations might belong to the category of cytogenetically unbalanced $X$ chromosomes which are preferentially inactive, regardless of the map position of the unbalanced segment. ${ }^{34-38}$ In contrast to the duplication mutation the PMD deletion mutation in patient PMD25 did not result in a skewed $X$ inactivation pattern. The most likely explanation would be that this deletion of about $100 \mathrm{~Kb}$ does not affect cell growth, as has been described in other deletions, such as those involving the FMRI and DMD genes, ${ }^{39,40}$ and unlike the $800 \mathrm{~kb}$ deletion in $\mathrm{Xq} 28 .{ }^{26}$

The PMD affected females have as yet unknown etiology. In these patients skewed $X$ inactivation would have suggested the involvement of an $X$-linked gene. A random pattern of $X$ inactivation, however, does not exclude it, since a skewed pattern in the CNS is a valid possibility.

A skewed pattern of $X$ inactivation was observed in two of five non-carrier females relatives. Although it may be due to a stochastic or age-related event, ${ }^{41}$ we suspected that in these families there could be another mutation that primarily affected the pattern of $X$ inactivation. To date, at least three loci have been suggested to affect the process of $X$ inactivation, ${ }^{25,26,42}$ but XIST is the only gene in which a mutation was shown to affect the choice of the inactive $X .{ }^{25}$ The recurrent mutation in the minimal promoter region of XIST ${ }^{24}$ was not found in any of the females with skewed $X$ inactivation including the non-carrier female relatives of PMD1 and PMD24 (not shown). However, we did not rule out another mutation in XIST.

We evaluated non-carrier female relatives in the study primarily to assess the $X$ inactivation assay as a possible diagnostic tool for identifying PMD carriers. However, since not all the proven duplication carriers had skewed $X$ inactivation, and in two out of fivenon-carrier relatives the $X$ inactivation was skewed, the pattern of $X$ inactivation is not reliable as a diagnosis of the carrier status in PMD.

\section{Acknowledgements}

We are grateful to the Wellcome Trust and Great Ormond Street Hospital Trustees for support (KW and KK). TB and WR were supported by funds from the Department of Veterans Affairs. Wethank
ME Hodes for providing samples and Graeme Suthers, Charles Schwartz and Melanie May for providing the DNA and mutation information for PMD14. Rodger Palmer and Tom Spencer are acknowledged for providing the BrdU incorporated fibroblast cell suspension for PMD1. John Wolff assisted with the studies on the deletion family.

\section{References}

1 Woodward K, Malcolm S: Proteolipid protein gene: PelizaeusMerzbacher disease in humans and neurodegeneration in mice. Trends Genet 1999; 15: 125-128.

2 Ellis D, Malcolm S: Proteolipid protein gene dosage effect in Pelizaeus-Merzbacher disease. Nat Genet 1994; 6: 333-334.

3 Sistermans EA, de Coo RF, De Vijs IJ, Van Oost BA: Duplication of the proteolipid protein gene is the major cause of PelizaeusMerzbacher disease. Neurol 1998; 50: 1749-1754.

4 Mimault C, Giraud G, Cortois V et al: Proteolipoprotein gene analysis in 82 patients with sporadic Pelizaeus-Merzbacher disease: duplications, the major cause of the disease, originate more frequently in male germ cells, but point mutations do not. Am J Hum Genet 1999; 65: 360-369.

5 Woodward K, Kendall E, Vetrie D, Malcolm S: Pelizaeus-Merzbacher disease: Identification of Xq22 proteolipid-protein duplications and characterization of breakpoints by interphase FISH. Am J Hum Genet 1998; 63: 207-217.

6 Strautnieks S, Rutland P, Winter RM, Baraitser M, Malcolm S: Pelizaeus-Merzbacher disease: detection of mutations $\mathrm{Thr}^{181} \rightarrow-$ Pro and Leu ${ }^{223} \rightarrow$ Pro in the proteolipid protein gene, and prenatal diagnosis. Am J Hum Genet 1992; 51: 871-878.

7 Raskind WH, Williams CA, Hudson LD, Bird TD: Complete deletion of the proteolipid protein gene (PLP) in a family with X-linked Pelizaeus-Merzbacher disease. Am J Hum Genet 1991; 49: 1355-1360.

8 Sistermanns EA, de Wijs IJ, de Coo RF, Smit LM, Menko FH, van Oost BA: A (G-to-A) mutation in the initiation codon of the proteolipid protein gene causing a relatively mild form of Pelizaeus-M erzbacher disease in a Dutch family. Hum Genet 1996; 97: 337-339.

9 Garbern JY, Cambi F, Tang XM et al: Proteolipid protein is necessary in peripheral as well as central myelin. Neuron 1997; 19: 205-218.

10 Hodes ME, DeMyer WE, Pratt VM, Edwards MK, Dlouhy SR: Girl with signs of Pelizaeus-Merzbacher disease heterozygous for a mutation in exon 2 of the proteolipid protein gene. Am J Med Genet 1995; 55: 397-401.

11 Nance MA, Boyadjiev S, Pratt VM, Taylor S, Hodes ME, Dlouhy SR: Adult-onset neurodegenerative disorder due to proteolipid protein gene mutation in the mother of a man with PelizaeusMerzbacher disease. Neurol 1996; 47: 1333-1335.

12 Hodes ME, Blank CA, Pratt VM, Morales J, Napier J, Dlouhy SR: Nonsense mutation in exon 3 of the proteolipid protein gene (PLP) in a family with an unusual form of Pelizaeus-Merzbacher disease. Am J Med Genet 1997; 69: 121-125.

13 Pamphlett R, Silberstein P: Pelizaeus-Merzbacher disease in a brother and sister. Acta Neuropathol (Berl) 1986; 69: 343-346.

14 Cassidy SB, Sheehan NC, Farrell DF, Grunnet M, Holmes GL, Zimmerman AW: Connatal Pelizaeus-Merzbacher disease: an autosomal recessive form. Pediatr Neurol 1987; 3: 300-305.

15 Nezu A, Kimura S, Uehara $S$ et al: Pelizaeus-Merzbacher-like disease: female case report. Brain Dev 1996; 18: 114-118.

16 Shimizu Y, Shioda K, Takada K, Minagawa M, Isshiki T: Female autopsy case of Seitelberger's connatal form of Pelizaeus-Merzbacher disease. No To Hattatsu 1997; 29: 507-513.

17 Belmont JW: Genetic control of X-inactivation and processes leading to X-inactivation skewing. Am J Hum Genet 1996; 58: 1101-1108. 
18 Thode A, Partington MW, Yip MY, Chapman C, Richardson VF, Turner G: A new syndrome with mental retardation, short stature and an Xq duplication. Am J Med Genet 1988; 30: 239-250.

19 Wells S, Mould S, Robins D, Robinson D, Jacobs P: Molecular and cytogenetic analysis of a familial microdeletion of Xq. J M ed Genet 1991; 28: 163-166.

20 Woodward K, Kendall E, Vetrie $D$ et al: Variation in PLP gene duplication causing disease. Am J Hum Genet 1998; 63 (supplement): A394, abstract No. 2287.

21 Allen CR, Zoghbi HY, Moseley AB, Rosenblatt HM, Belmont JW: Methylation of Hpall and Hhal sites near the polymorphic CAG repeat in the human androgen-receptor gene correlates with $X$ chromosome inactivation. Am J Hum Genet 1992; 51: 1229-1239.

22 Hendriks RW, Chen Z-Y, Hinds H, Schuurman RKB, Craig IW: An $X$ chromosome inactivation assay based on differential methylation of $\mathrm{CpG}$ island coupled to a VNTR polymorphism at the 5 ' end of the monoamine oxidase A gene. Hum Mol Genet 1992; 1: 187-194.

23 Rooney DE, Czepulkowski BH: Blood lymphocytes culture for the expression of differential replication and sister chromatide exchange: setting up. In: Rickwood D (ed). Human Chromosome Preparation, Essential Technique, John Wiley: Chichester, UK: 1997; p 53.

24 Naumova AK, Plenge RM, Bird LM et al: Heritability of $X$ chromosome - inactivation phenotype in a large family. Am J Hum Genet 1996; 58: 1111-1119.

25 Plenge RM, Hendrich BD, Schwartz C, RM et al: A promoter mutation in the XIST gene in two unrelated families with skewed X-chromosome inactivation. Nat Genet 1997; 17: 353-356.

26 Pegoraro E, Whitaker J, Mowery-Rushton P, Surti U, Lanasa M, Hoffman EP: Familial skewed $X$ inactivation: A molecular trait associated with high spontaneous-abortion rate maps to Xq28. Am J Hum Genet 1997; 61: 160-170.

27 Ørstavik KH, Ørstavik RE, Naumova AK et al: X chromosome inactivation in carriers of Barth syndrome. Am J Hum Genet 1998; 63: 1457-1463.

28 Migeon BR: Non-random $X$ chromosome inactivation in mammalian cells. Cytogenet Cell Genet 1998; 80: 142-148.

29 Migeon BR, Haisley-Royster C: Familial skewed $X$ inactivation and $X$-linked mutations: unbalanced $X$ inactivation is a powerful means to ascertain $X$-linked genes that affect cell proliferation. Am J Hum Genet 1998; 62: 1555-1557.
30 Carango P, Funanage VL, Quiros RE, Debruyn CS, Marks HG: Overexpression of DM20 messenger RNA in two brothers with Pelizaeus-Merzbacher disease. Ann Neurol 1995; 38: 610-617.

31 Cuddon PA, Lipsitz D, Duncan ID: Myelin mosaicism and brain plasticity in heterozygous females of a canine X-lined trait. Ann Neurol 1998; 44: 771-779.

32 Filosa S, Giacometti N, Wangwei $C$ et al: Somatic-cell selection is a major determinant to the blood cell phenotype in heterozygotes for glucose-6-phosphate dehydrogenase mutations causing severe enzyme deficiency. Am J Hum Genet 1996; 59: 887-895.

33 Plenge RM, Tranebjaerg $L$, Jensen PKA, Schwartz C, Willard HF: Evidence that mutations in the $\mathrm{X}$-linked DDP gene cause incompletely penetrant and variable skewed $\mathrm{X}$ inactivation. Am J Hum Genet 1999; 64: 759-767.

34 Tuck-Muller CM, Martinez JE, Batista DA, Kearns WG, Wertelecki W: Duplication of the short arm of the $\mathrm{X}$ chromosome in mother and daughter. Hum Genet 1993; 91: 395-400.

35 Vasquez Al, Rivera $\mathrm{H}$, Bobadilla L, Crolla JA: A familial $\mathrm{Xp}^{+}$ chromosome, dup (Xq26.3 $\rightarrow$ qter). J Med Genet 1995; 32: 891-893.

36 Jalal SM, Dahl R, Erickson L, Zimmerman D, Lindor N: Cytogenetic and clinical characteristics of a case involving complete duplication of Xpter $\rightarrow$ Xq13. J Med Genet 1996; 33: 237-239.

37 Garcia-Heras J, Martin JA, Day DW, Scacheri P, Witchel SF: 'De novo' duplication Xq23 $\rightarrow$ Xq26 of paternal origin in a girl with a mildly affected phenotype. Am J Med Genet 1997; 70: 404-408.

38 Zhang A, Weaver DD, Palmer CG: Molecular cytogenetic identification of four X chromosome duplications. Am J Med Genet 1997; 68: 29-38.

39 Schmidt $M$, Robertson A, Crawford M: X inactivation pattern in interstitial deletions of the fragile X region. Am J Med Genet 1994; 51: 451.

40 Tihy $F$, Vogt $N$, Recan $D$ et al: Skewed inactivation of an $X$ chromosome deleted at the dystrophin gene in an asymptomatic mother and her affected daughter. Hum Genet 1994; 93: 563-567.

41 Busque L, Mio R, Mattioli J et al: Nonrandom X-inactivation patterns in normal females: Iyonization ratios vary with age. Blood 1996; 88: 59-65.

42 Naumova AK, Olien L, Bird LM et al: Genetic mapping of X-linked loci involved in skewing of $X$ chromosome inactivation in the human. Eur J Hum Genet 1998; 6: 552-562. 